\title{
Effect of Computation Domain on Simulation of Small Compartment Fires
}

\author{
YAPING HE, CHRIS JAMIESON, ALAN JEARY and JIAN WANG ${ }^{1}$ \\ School of Engineering \\ University of Western Sydney \\ Locked Bag 1797, Penrith South DC, NSW 1797, Australia \\ ${ }^{1}$ State Key Laboratory of Fire Science \\ University of Science and Technology of China \\ Heifei, P. R. China
}

\begin{abstract}
This paper presents a numerical exercise to investigate the effect of computation domain on simulation of compartment fires. Fire Dynamics Simulator was used to model steady state propane fires in a small compartment. The computation domain varied with its boundary set at the compartment wall containing an opening and extended beyond the wall at various distances. Simulations were conducted with different vent opening sizes and heat release rates. Both fuel controlled and ventilation controlled fire scenarios were investigated. The grid dependence and domain dependence were cross checked. It was demonstrated that there were significant differences in the predicted parameters between the domains with extensions and those without. Recommendations are provided on the basis of the current study for domain selection for the simulation of compartment fires.
\end{abstract}

KEYWORDS: compartment fires, modelling, grid sensitivity, domain dependence, fire dynamics simulator

\section{NOMENCLATURE LISTING}

\begin{tabular}{|c|c|c|c|}
\hline$A$ & area of vent opening $\left(\mathrm{m}^{2}\right)$ & $x$ & $x$-coordinate $(\mathrm{m})$ \\
\hline$D^{*}$ & characteristic fire diameter (m) & $y$ & $y$-coordinate (m) \\
\hline$D_{H}$ & hydraulic diameter of opening (m) & $Z$ & $z$-coordinate (m) \\
\hline$H$ & height of vent opening (m) & & \\
\hline $\mathcal{H}$ & total pressure divided by density $\left(\mathrm{m}^{2} \mathrm{~s}^{-2}\right)$ & & \\
\hline$P$ & perimeter of vent opening (m) & & \\
\hline$Q$ & specified total heat release rate $(\mathrm{kW})$ & Greek & \\
\hline$Q_{v}$ & ventilation controlled heat release rate $(\mathrm{kW})$ & $\Delta$ & domain extension (m) \\
\hline$R$ & correlation coefficient & $\delta$ & grid size $(\mathrm{m}, \mathrm{mm})$ \\
\hline$T$ & temperature $\left(\mathrm{K},{ }^{\circ} \mathrm{C}\right)$ & & \\
\hline$t$ & time $(\mathrm{s})$ & \multicolumn{2}{|c|}{ subscripts } \\
\hline$U$ & $U$-velocity $\left(\mathrm{ms}^{-1}\right)$ & $x, y, z$ & that in $x$ or $y$ or $z$ direction \\
\hline $\mathrm{u}$ & Velocity $\left(\left(\mathrm{ms}^{-1}\right)\right.$ & & \\
\hline
\end{tabular}

\section{INTRODUCTION}

Fire safety engineering is a relatively young field which draws on a wide range of scientific and technological expertise to analyse fires in the built environment. Fire safety engineers provide performance based fire protection solutions which facilitate a greater degree of flexibility and safety in building design. The introduction of performance based building codes has led to the rapid growth of fire engineering both commercially and academically.

Compartment fire modelling is used by fire safety engineers to assess the impact of fires and the effectiveness of fire safety measures for building designs. There are many fire models available to the fire engineering community which are constantly evolving and becoming more accessible with advances in research and computational power. The verification and validation of fire models is imperative so that users have a clear understanding of the accuracy and limitations of these models. Much effort has been made in 
computer model validations against experimental results and such effort is a lifetime exercise as far as the computer models are concerned [1][2]. However, the technical validity of the models is only one aspect of the question about the model application, validity and accuracy. The other main aspect involves the appropriateness of user-specified input and the proper construction of the model setup. In particular, the appropriate specification of boundary conditions and the associated problem of computational domain dependence are crucial to the validity, accuracy and/or fidelity of the computational results. In the past, focus has often been applied to the analysis of grid size dependence [3][4][5] and insufficient attention has been devoted to the selection of the size and extent of the domain analysed. This is referred to in this paper as the computational domain. In their validation exercise for prediction of pool fires, Wen et al [6] cautioned on the issue of computational domain. This caution should extend to the wider range of fire scenarios.

Computer model users are sometimes pressed for timely delivery of results and it is not an uncommon practice to minimize computational cost in terms of memory space and computation time by setting what was thought the acceptable computational grid size and domain and by agglomerating the computational domain with the building physical domain. However, the "corners" may sometimes be unwittingly cut at the expense of losing accuracy and even affecting the validity or fidelity of the results.

The issue of setting appropriate computational domains was recently investigated by Wu et al [7] for small, fuel-controlled, single-room fires. Significant differences were observed between the results obtained from the original room size domain and that from extended domains. The results were compared with that of the single-room fire experiment by Steckler et al [8]. The extended domains were shown to produce better agreement with the experiment than the non-extended domain. The appropriate extent of the domain extension was shown to be proportional to the heat release rate of the fire involved. Wu et al [7] concluded that generally, the computation domain should be extended beyond the physical or geometric boundary of the building enclosure, when there is an opening in the boundary. They also recommended that a domain dependence study should be conducted in numerical simulations of building fires in order to verify the computational accuracy and validity. The question still remains as to the extent of increase necessary in the computational domain for a given building geometry. General guidance may be desirable in order to minimize the number of simulation runs in a domain dependence study.

This paper reports an investigatory study into the problem of computational domain selection for fire simulation using the Fire Dynamics Simulator 5 (FDS5) [9] developed by the National Institute of Standards and Technology, USA.

\section{FIRE DRIVEN VENT FLOW AND ITS SIMULATION}

The flow of gases through a vent from a room containing a fire is driven by the pressure difference between the room and the surroundings [10]. A fire in a compartment results in the formation of a hot upper layer consisting of a mixture of combustion products and entrained air, and a cold lower layer consisting of air. The two zone or stratified conditions within an enclosure will continue until the smoke layer drops to the floor, or flashover occurs. In this case, the conditions within the room can be described as well mixed and the temperature is assumed to be uniform throughout the enclosure. A counter-current flow field is created under the natural ventilation condition as shown in Fig. 1 . The flow velocity distribution is closely related to the pressure distribution around the vent and is strongly influenced by the turbulent shear movement of the counter-current flows and the interactions between the flow and the vent edges. Velocity distributions have been observed to vary in both horizontal and vertical directions [11][12].

The boundary conditions at the computational domains for the simulation of vent flows are usually set as open boundary with constant pressure. The Fire Dynamic Simulator model allows users to create vent openings to the outside of a compartment by specifying a VENT with SURF_ID = 'OPEN' in the exterior boundary of the computational domain. FDS uses a constant pressure assumption at OPEN boundaries. At open external boundaries pressure is determined based on whether the flow is outgoing or incoming:

$$
\begin{array}{ll}
\mathcal{H}=|U|^{2} / 2 & \text { outgoing } \\
\mathcal{H}=0 & \text { incoming }
\end{array}
$$

where $\mathcal{H}$ is the total pressure divided by density. 


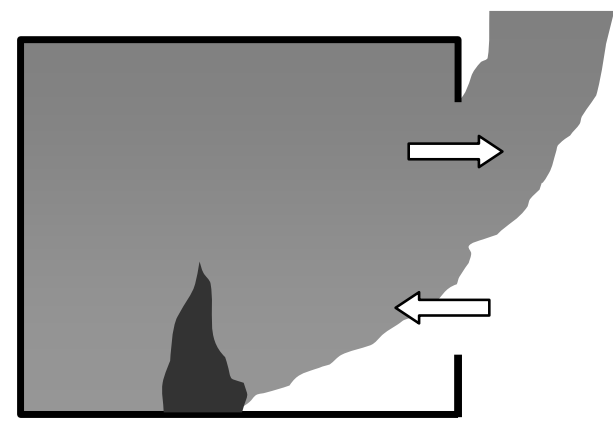

Fig. 1. Pressure difference across the vent for the well-mixed ideal case.

The outgoing boundary condition assumes that the turbulence diminishes at an outgoing boundary and the corresponding pressure perturbation is zero and that $\mathcal{H}$ is constant along streamlines. The incoming boundary condition assumes that the pressure perturbation is zero infinitely far away [13]. It has been stated in the FDS verification and validation guide [14] that the constant pressure assumption at open boundaries "will affect the plume behaviour if the boundary of the computational domain is too close to the plume". A vent flow also forms a plume outside the vent. By setting the boundary of the computation domain at the vent of a compartment, the vent plume and its disturbance to the pressure distribution immediate outside the vent is neglected. The question will then arise as to whether the computation of the fire combustion inside the compartment and the resulting conditions is affected. Little discussion and guidance is found in the literature for users.

To minimise the effect of the constant pressure assumption on results, it is a good practice to expand the computational domain beyond the vent openings rather than having the OPEN vent directly into the enclosure. This is achieved by extending the computational domain beyond the opening and specifying OPEN vents to the boundaries of the area outside the enclosure. It is generally considered important for small enclosures where the fire is in close proximity to the opening or where openings are used for venting of smoke [7].

Whilst modelling some external space is good practice, exactly how much external space is required to obtain reasonable results inside the room is still not documented. Modelling too much external space will waste computational time and may require users to increase cell size as a result. Conversely, not modelling enough external space may not address the accuracy issues associated with the OPEN vents.

\section{PARAMETRIC STUDY}

A numerical FDS experiment involving a small room with a centrally located fire and a single opening was conducted. The fire source was a $0.8 \mathrm{~m} \times 0.8 \mathrm{~m}$ propane burner. The room had a dimension of $4 \mathrm{~m} \times 4 \mathrm{~m} \times 2.5 \mathrm{~m}$ and an opening as shown in Fig. 2. The bounding walls were assumed infinitely thin (inert). The ceiling was concrete. All solid surfaces were non-slip. Initially, the computational domain was set to coincide with the size of the room. The computational domain was subsequently extended in $x$ and $z$ directions.

The numerical experiment involved two steps. Firstly, a grid dependence study was conducted prior to the study of domain dependence. The fire heat release rate and opening size were also varied between simulations. In each numerical experimental case or simulation run, the heat release rate was set constant and both the ambient and initial temperatures were set at $20{ }^{\circ} \mathrm{C}$. No external wind was considered in the study. The large eddy simulation (LES) scheme was used for turbulence modelling.

The output data for a range of parameters including temperature, velocity and pressure were compared to reveal the impact of varying domain size and other parameters on the output of the simulations. Detailed factorial designs of the two parts of the numerical study and the results are given in the following subsections. The results presented in the following were obtained after quasi steady states were reached, i.e., when the predicted mean quantities stopped exhibiting variations with time. 


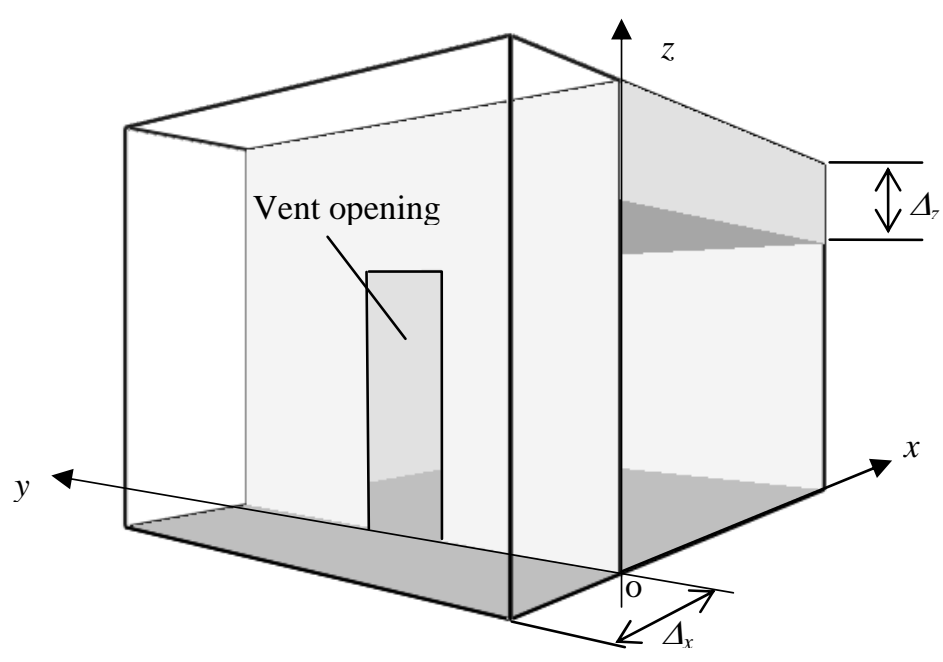

Fig. 2. Expansion of computational domain outside of the open vent.

\section{Grid Independence}

To eliminate or minimize grid dependence while investigating domain dependence, the grid sensitivity study was conducted with two fire heat release rates and two domain sizes. The room dimension for the grid sensitivity was $4 \mathrm{~m} \times 4 \mathrm{~m} \times 2.4 \mathrm{~m}$, which was slightly smaller than the room used in the domain dependence study. The implications of the small difference in room sizes between the two studies were deemed negligible. The door dimension in the grid sensitivity study was $0.8 \times 2.1 \mathrm{~m}$. A summary of simulation conditions of grid sensitivity study is given in Table 1 . The grid dependence was also crosschecked with domain dependence for one extended domain case in which the computational domain was extended by $1.2 \mathrm{~m}$ beyond the vent opening of the compartment.

Table 1. Summary of simulation conditions of grid sensitivity study.

\begin{tabular}{|c|c|c|c|}
\hline$Q(\mathrm{~kW})$ & $D^{*}(\mathrm{~m})$ & $\delta x(\mathrm{~m})$ & $D^{*} / \delta x$ \\
\hline \multirow{3}{*}{250} & \multirow{3}{*}{0.55} & 0.20 & 2.75 \\
\cline { 3 - 4 } & & 0.10 & 5.5 \\
\cline { 3 - 4 } & & 0.08 & 6.875 \\
\cline { 3 - 4 } & \multirow{3}{*}{500} & 0.05 & 11.0 \\
\hline \multirow{3}{*}{0.72} & 0.20 & 3.6 \\
\cline { 3 - 4 } & & 0.10 & 7.2 \\
\cline { 3 - 4 } & & 0.08 & 9.0 \\
\cline { 3 - 4 } & & 0.05 & 14.4 \\
\hline
\end{tabular}

The characteristic fire diameter was evaluated according to the formula given in Dreisbach and Hill [15]. The grid sizes in all dimensions were kept the same throughout this study (i.e., $\delta x=\delta y=\delta z$ ). The simulations listed in Table 1 were repeated with zero and $1.2 \mathrm{~m}$ domain extensions in $x$ direction.

The predicted temperature vertical profiles at the centre of the room with various grid sizes, with and without domain extension are compared in Fig. 3. The correlation coefficients between the predicted individual temperature profiles using given grid sizes and the average of all temperature profiles are also presented in this figure. 


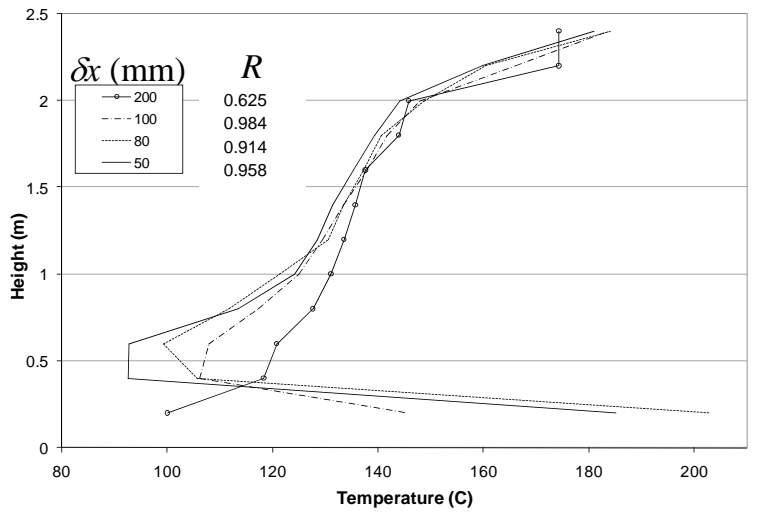

(a) $\Delta_{x}=0 \mathrm{~m}$

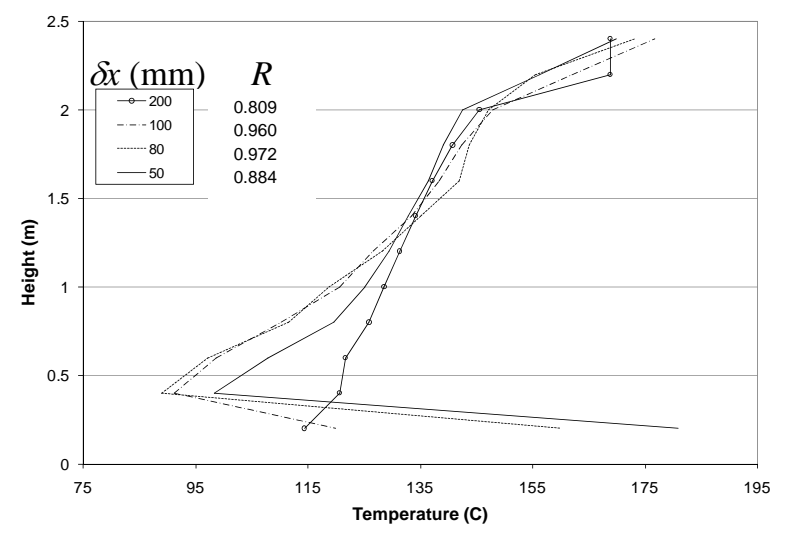

(b) $\Delta_{x}=1.2 \mathrm{~m}$

Fig. 3. Comparison of predicted temperature distributions at the centre of the room with various grid sizes and two domain extensions $(Q=250 \mathrm{~kW})$.

It can be seen from the above figure that the temperature profile for the $200 \mathrm{~mm}$ cell size has the lowest correlation coefficient and is significantly different from the predicted temperature profiles using smaller cell sizes for both the zero and $1.2 \mathrm{~m}$ domain extension simulations. The $200 \mathrm{~mm}$ cell size did not predict the high temperatures at the base of the plume due to flaming, which can be seen in the smaller cell sizes. On the other hand, all simulations with $50 \mathrm{~mm}, 80 \mathrm{~mm}$ and $100 \mathrm{~mm}$ cell sizes produced similar temperature profiles with a peak temperature at $0.2 \mathrm{~m}$ above floor level, a significant drop in temperature at $0.4 \mathrm{~m}$ above the floor and then a gradual rise in temperature towards the ceiling. The $50 \mathrm{~mm}$ and $80 \mathrm{~mm}$ cell sizes resulted in the highest temperatures at the base of the fire. The simulation with the extended domain and a $50 \mathrm{~mm}$ cell size predicted higher temperatures between $0.4 \mathrm{~m}$ and $1 \mathrm{~m}$ above ground level compared to other cell sizes.

Similar observations were made from the temperature results of simulations with $500 \mathrm{~kW}$ heat release rate as presented in Fig. 4.

The predicted $u$-velocity profiles at the centre of the room door with various grid sizes, with zero and $1.2 \mathrm{~m}$ domain extensions are compared in Fig. 5. The correlation coefficients between the predicted individual velocity profiles using given grid sizes and the average of all velocity profiles are also presented in this figure.

It can be seen from Fig. 5 that the $200 \mathrm{~mm}$ cell has the lowest correlation coefficient and is significantly different from the predicted velocity profiles suing smaller cell sizes for both the zero and $1.2 \mathrm{~m}$ domain extension simulations. The $200 \mathrm{~mm}$ cell size produced higher incoming velocities and lower outgoing velocities when compared to the smaller grid resolutions. It also failed to predict the 'S' shaped velocity profile across the door that can be seen in the results for $100 \mathrm{~mm}, 80 \mathrm{~mm}$ and $50 \mathrm{~mm}$ cell sizes. This is because the coarse grid was probably larger than the thickness of the boundary layer flow at the door jamb and, therefore, could not resolve the boundary layer flow. As the smaller grids resolved the boundary layer flow better, the ' $S$ ' shaped profile was better pronounced and both the maximum outgoing velocity and the neutral plane height tended to increase as the cell size was reduced. The incoming velocity through the door opening decreased as the cell size was reduced for the simulations. It is also seen that the overall velocity profile did not change significantly for grid sizes of $100 \mathrm{~mm}, 80 \mathrm{~mm}$ and $50 \mathrm{~mm}$, particularly when the computational domain was extended. Similar observations were also made for the velocity results of simulations with $500 \mathrm{~kW}$ heat release rate. 


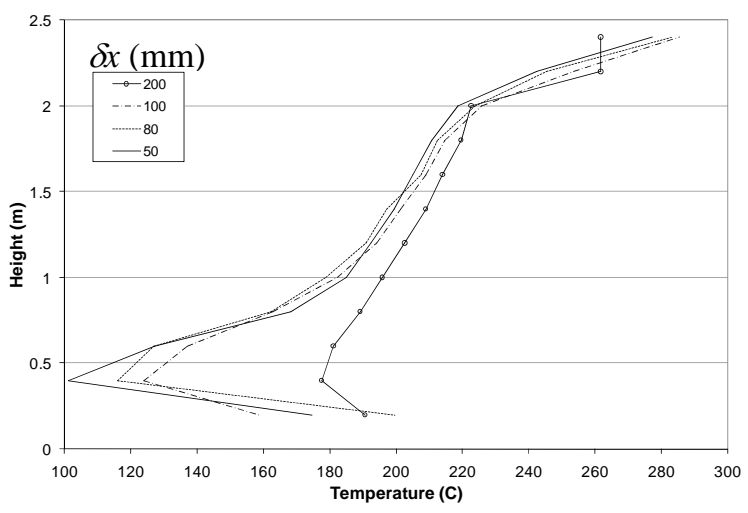

(a) $\Delta_{x}=0$

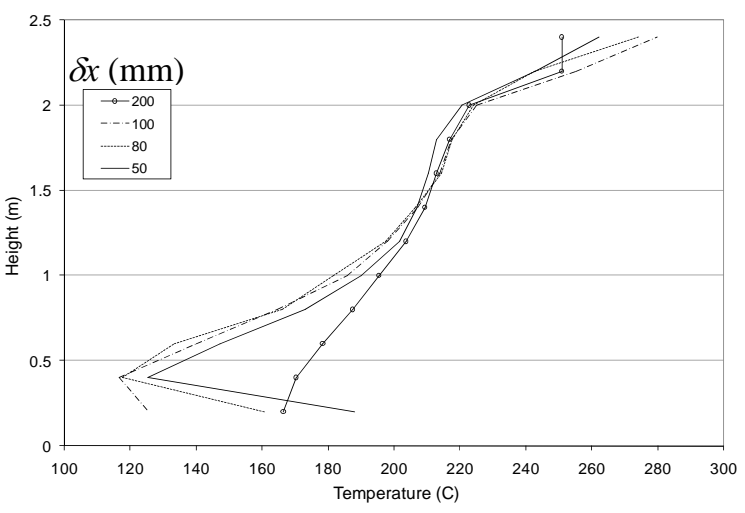

(b) $\Delta_{x}=1.2 \mathrm{~m}$

Fig. 4. Comparison of predicted temperature distributions at the centre of the room with various grid sizes and two domain extensions $(Q=500 \mathrm{~kW})$.

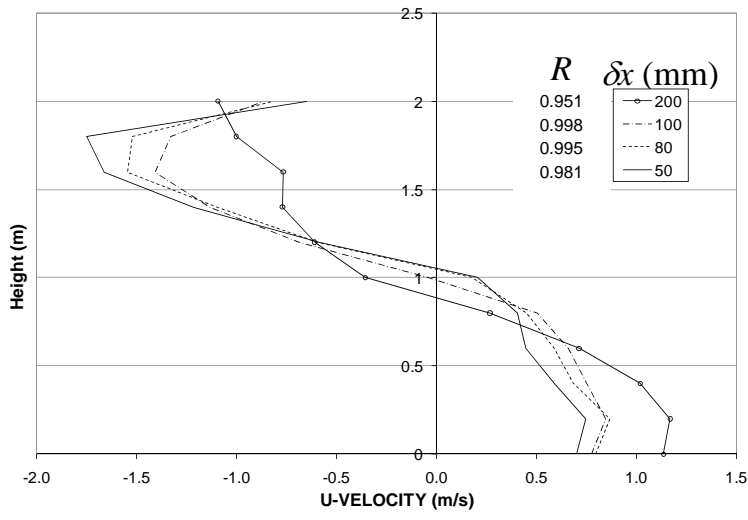

(a) $\Delta_{X}=0$

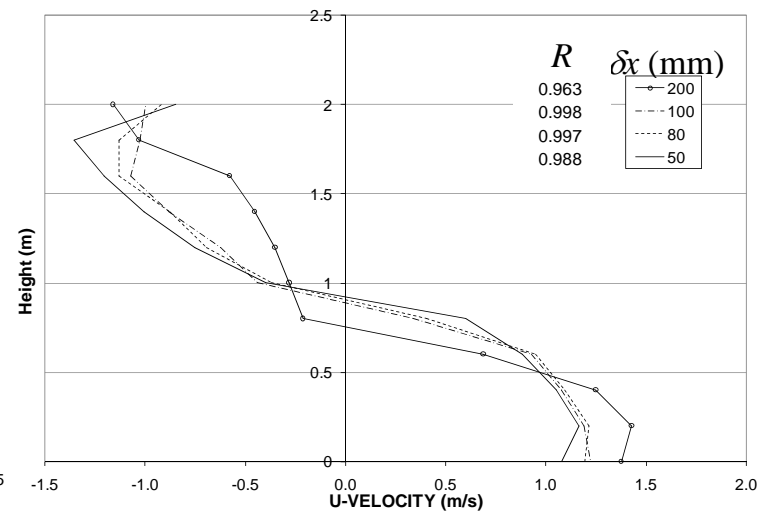

(b) $\Delta_{x}=1.2 \mathrm{~m}$

Fig. 5. Comparison of predicted velocity distributions at the centre of the door with various grid sizes and two domain extensions $(Q=250 \mathrm{~kW})$.

In summary, whilst the 200mm cell size simulations predicted significantly different results and displayed poor solution fidelity, there were minimal differences between the $100 \mathrm{~mm}, 80 \mathrm{~mm}$ and $50 \mathrm{~mm}$ grids. This suggests that a $100 \mathrm{~mm}$ cell size is adequate. However, for the simulations where no exterior is modelled, the velocity results are not as well resolved, particularly in terms of the peak velocity through the opening.

In light of the uncertainty associated with simulations where no exterior was modelled and the benefit of the finer mesh in terms of fidelity, the $50 \mathrm{~mm}$ grid size was selected for the domain dependence study. It is noted that the $50 \mathrm{~mm}$ grid corresponds with the recommended size of $D^{*} / 10$ for the $250 \mathrm{~kW}$ fire, the minimum heat release rate used in the domain dependence study. It has been suggested by Dreisbach and Hill [15] that for most fire safety engineering applications, a $D^{*} / \delta x$ ratio of between 5 and 10 will produce an adequately resolved solution within a reasonable computational timeframe. Although a less dense grid may be acceptable for the $500 \mathrm{~kW}$ and $1000 \mathrm{~kW}$ fire sizes, the same grid size was maintained to limit the number of variables altered between cases. A $100 \mathrm{~mm}$ grid was used for the $4000 \mathrm{~kW}$ simulation because of the significantly larger characteristic fire diameter. 


\section{Domain Dependence}

Multiple series of simulation runs were carried out to investigate the domain dependence for various heat release rates and opening configurations. In each series the computational domain varied. The room dimension for this exercise was $4 \mathrm{~m} \times 4 \mathrm{~m} \times 2.5 \mathrm{~m}$ with a single vent opening. Two vent opening sizes, representing a door or a window, were considered. The fire scenario in the room varied from fuel controlled (over-ventilated) combustion to ventilation controlled (under-ventilated) combustion. A summary of simulation conditions for the run series is given in Table 2. The maximum ventilation controlled heat release rate in the room was estimated from the following equation [10]

$$
Q_{v}=1.5 A \sqrt{H} \quad(\mathrm{MW})
$$

Table 2. Simulation conditions.

\begin{tabular}{|c|c|c|c|c|c|c|}
\hline Series No. & Vent size $(\mathrm{m})$ & Sill $(\mathrm{m})$ & $D_{H}(\mathrm{~m})$ & $Q_{v}(\mathrm{~kW})$ & $Q(\mathrm{~kW})$ & $Q / Q_{v}$ \\
\hline 1 & $0.8 \times 2.1$ & 0 & 1.16 & 3650 & 250 & 0.07 \\
\hline 2 & $0.8 \times 2.1$ & 0 & 1.16 & 3650 & 500 & 0.14 \\
\hline 3 & $0.8 \times 2.1$ & 0 & 1.16 & 3650 & 1000 & 0.27 \\
\hline 4 & $0.8 \times 2.1$ & 0 & 1.16 & 3650 & 4000 & 1.10 \\
\hline 5 & $0.6 \times 1.0$ & 0.75 & 0.75 & 900 & 250 & 0.28 \\
\hline 6 & $0.6 \times 1.0$ & 0.75 & 0.75 & 900 & 500 & 0.56 \\
\hline 7 & $0.6 \times 1.0$ & 0.75 & 0.75 & 900 & 1000 & 1.11 \\
\hline
\end{tabular}

The amount of domain extension was determined on the basis of hydraulic diameter, $D_{H}$, of the opening, which is defined as

$$
D_{H}=\frac{4 A}{P}
$$

In each series of simulations the domain was extended in both $x$ and $z$ directions by zero, 1 cell size and approximately a quarter, a half, 3 quarters and the full length of the hydraulic diameter $D_{H}$. The extensions in the two directions were equal (i.e., $\Delta_{x}=\Delta_{z}$, see Fig. 2 ) in each simulation run. Table 3 gives a summary of the extent of domain extension.

Table 3. Summary of Extent of domain extension.

\begin{tabular}{|c|c|c|c|}
\hline \multicolumn{2}{|c|}{ Door vent cases } & \multicolumn{2}{c|}{ Window vent cases } \\
\hline$\Delta_{X}(\mathrm{~m})$ & $\Delta_{X} / D_{H}$ (approximate) & $\Delta_{X}(\mathrm{~m})$ & $\Delta_{X} / D_{H}$ (approximate) \\
\hline 0 & 0 & 0 & 0 \\
\hline $0.05(1$ cell $)$ & $1 / 25$ & $0.05(1$ cell $)$ & $1 / 15$ \\
\hline 0.3 & $1 / 4$ & 0.2 & $1 / 4$ \\
\hline 0.6 & $1 / 2$ & 0.4 & $1 / 2$ \\
\hline 0.9 & $3 / 4$ & 0.6 & $3 / 4$ \\
\hline 1.2 & 1 & 0.75 & 1 \\
\hline
\end{tabular}

The results of doorway velocity profiles and room corner temperature profiles from various simulation series are presented and compared in Fig. 6. The correlation coefficients between the predicted individual profiles using given domain extensions and the average of all profiles are also presented in this figure. 


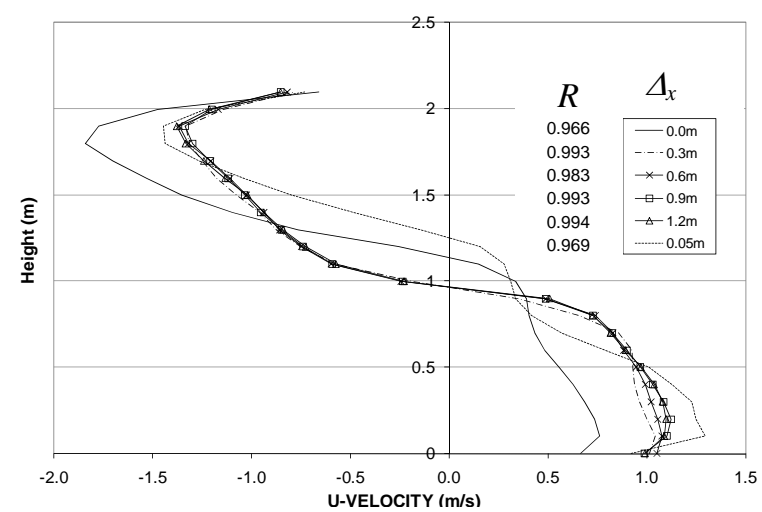

(a) Velocity profile at the door, $Q=250 \mathrm{~kW}$.

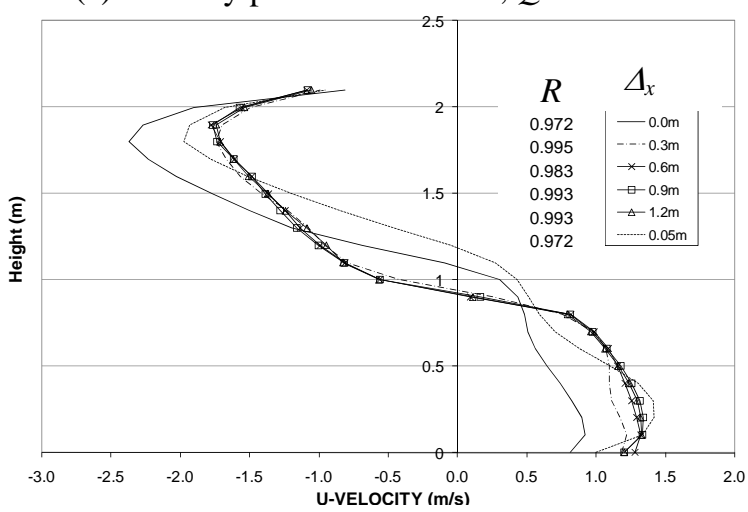

(c) Velocity profile at the door, $Q=500 \mathrm{~kW}$.

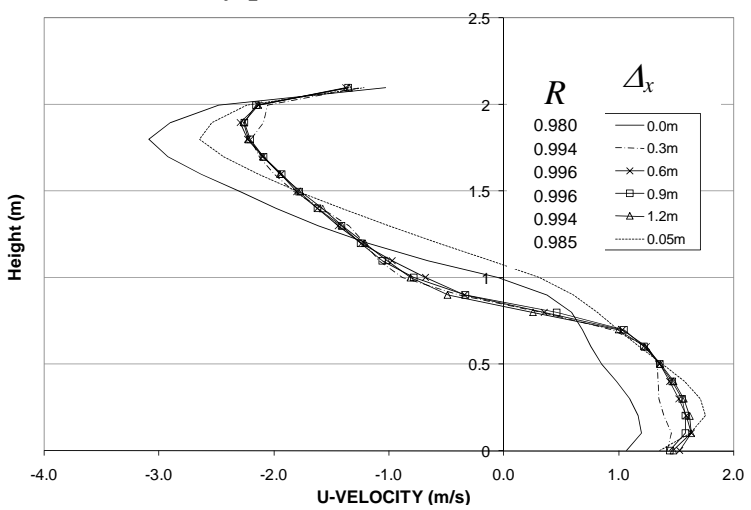

(e) Velocity profile at the door, $Q=1000 \mathrm{~kW}$.

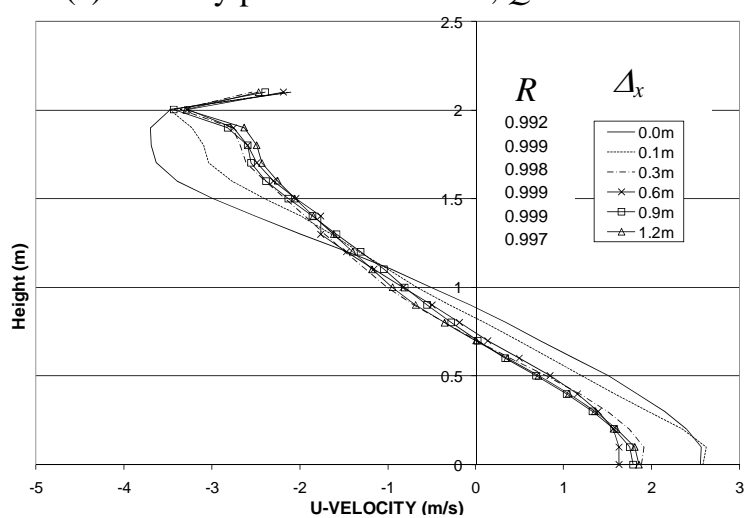

(g) Velocity profile at the door, $Q=4000 \mathrm{~kW}$.

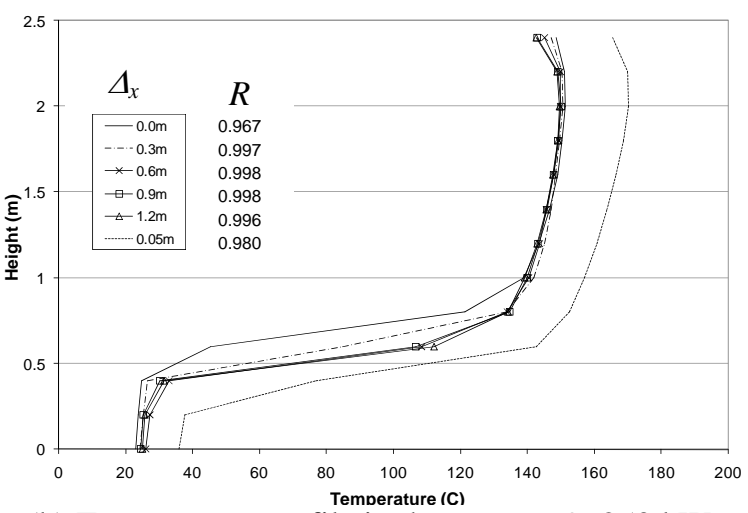

(b) Temperature profile in the corner, $Q=250 \mathrm{~kW}$.

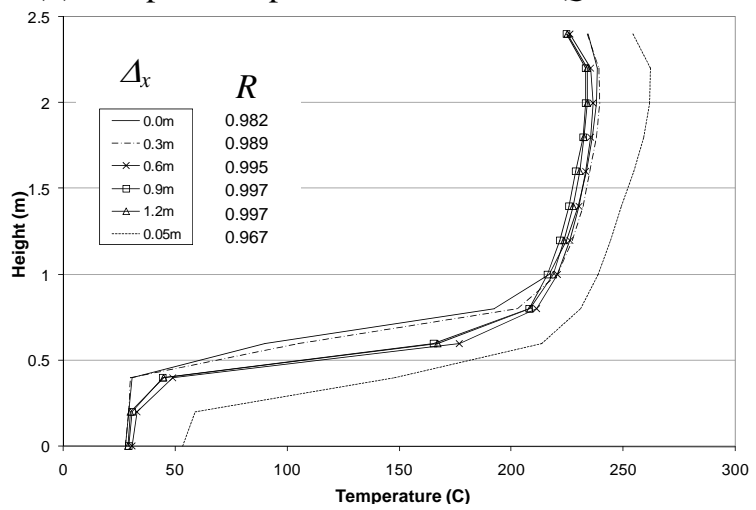

(d) Temperature profile in the corner, $Q=500 \mathrm{~kW}$.

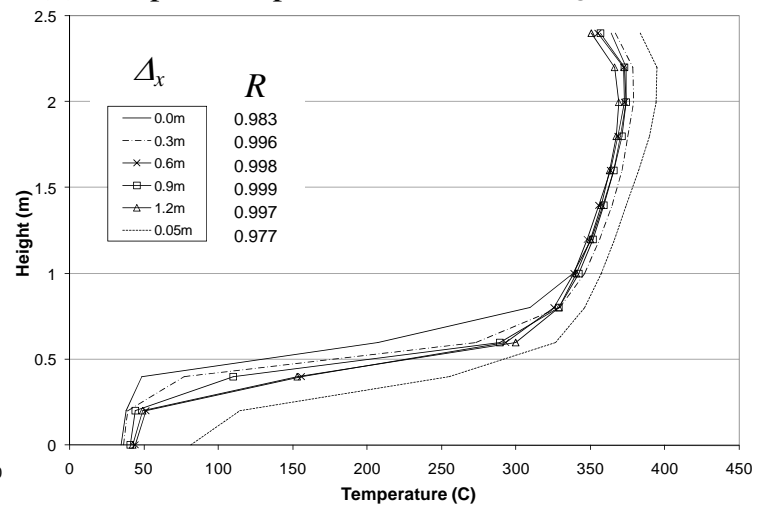

(f) Temperature profile in the corner, $Q=1000 \mathrm{~kW}$.

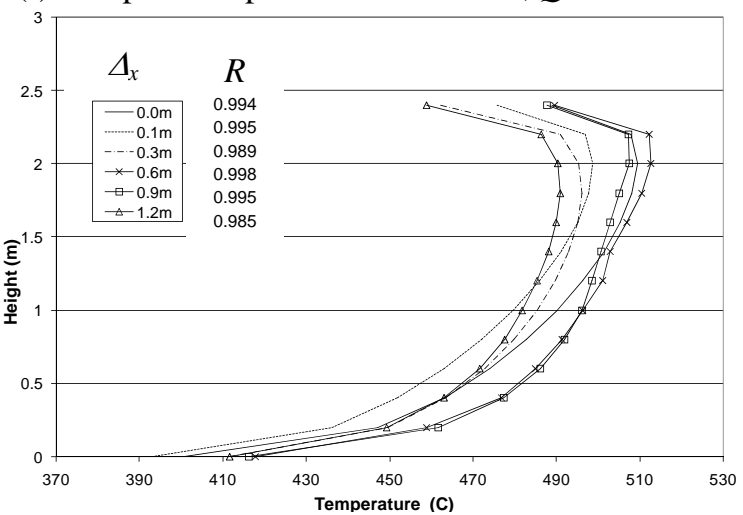

(h) Temperature profile in the corner, $Q=4000 \mathrm{~kW}$.

Fig. 6. Comparison of predicted parameter profiles using various domain extensions (the door vent). 
The following observations are noted:

- With the exception of the $0 \mathrm{~m}$ and $0.05 \mathrm{~m}$ domain extension, all simulations show good agreement.

- Both the velocity and temperature profiles indicate that the simulated $0 \mathrm{~m}$ domain extension yielded higher smoke layer interface than all other cases.

- The zero and one-cell extensions over-estimated the out-flow velocity in the upper part of the vent and under estimated the in-flow velocity in the lower part.

- The $0.3 \mathrm{~m}$ domain extension simulation shows a relatively minor deviation from the other profiles between $0.4 \mathrm{~m}$ and $0.8 \mathrm{~m}$ above floor level.

- The $0.6 \mathrm{~m}, 0.9 \mathrm{~m}$ and $1.2 \mathrm{~m}$ simulations all show good agreement throughout the height of the room.

- As far as the temperature profile is concerned, the deviation of the $0.05 \mathrm{~m}$ (or one-cell) extension from the main body of the profiles was greater than that for the $0 \mathrm{~m}$ extension.

- The above observations are applicable to the range of fire heat release rate investigated.

The situation with the smaller window opening case, as revealed in Fig. 7, is not much different from that of the door case.

The difference in doorway velocity profile would signify that the difference in gas in-flow and out-flow rates would lead to the difference in the calculated heat release rate inside the room of a ventilation controlled fire. Figure 8 shows the predicted total heat release rate and the heat release rate inside the room using various domain extensions. The specified total heat release rate was $4000 \mathrm{~kW}$. As the domain extension was increased, the predicted total heat release rate approached the specified total heat release rate since more space was created to capture the continued combustion outside the room. The heat release rate inside the burn-room was also approaching that of the ventilation controlled limit of $3650 \mathrm{~kW}$ as the domain extension was increased, except for the largest extension case where the predicted heat release rate exhibited a drop. The reason for this is not fully understood at the moment. It is speculated that the oversupply of fuel gas inside the burn room might have reduced the air supply rate through the door, thereby reducing the heat release rate. This phenomenon may have been better simulated by the large extended domain.

\section{DISCUSSION}

The FDS simulations conducted demonstrate that varying the domain extension outside an opening into a fire enclosure has an impact on the results inside the enclosure for both fuel and ventilation controlled fires.

When the boundary of the computational domain was set at the opening of the fire compartment, the simulation results were inconsistent with the results of the simulations where the domain was extended beyond the opening.

As the domain extension beyond the opening was increased the results generally became more consistent within the enclosure. This finding confirmed the finding by Wu et al [7] for fuel controlled enclosure fires. Further more, the current results inside the enclosure of ventilation controlled fires showed reasonable agreement where the computational domain was extended by half the hydraulic diameter of the opening, or more.

The results obtained by extending the computational domain by the width of a single grid cell beyond an opening also showed poor agreement with the results where more external space was modelled. In many cases the results of the simulations where the domain was extended by one grid cell beyond the opening showed poorer agreement than the simulations with no domain extension.

The maximum ventilation controlled heat release rate with the enclosure was limited by the amount of external space modelled. Where no external space was modelled, the ventilation controlled heat release rate was approximately $15 \%$ lower than the simulations where external space was modelled. 


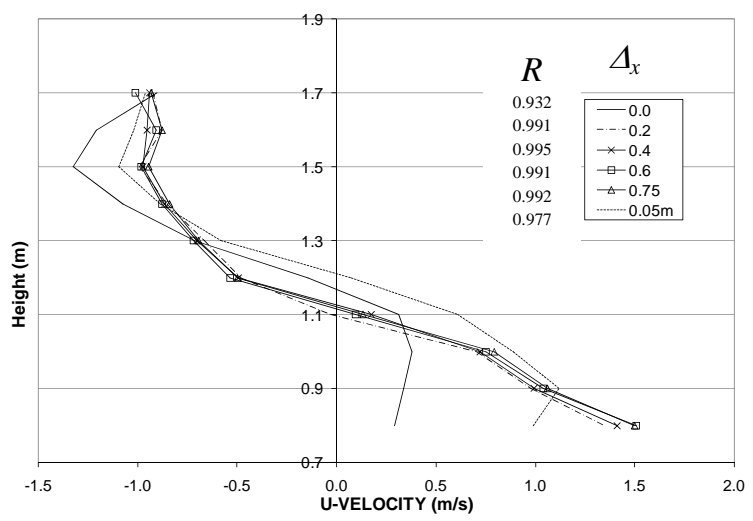

(a) Velocity profile at the window, $Q=250 \mathrm{~kW}$.

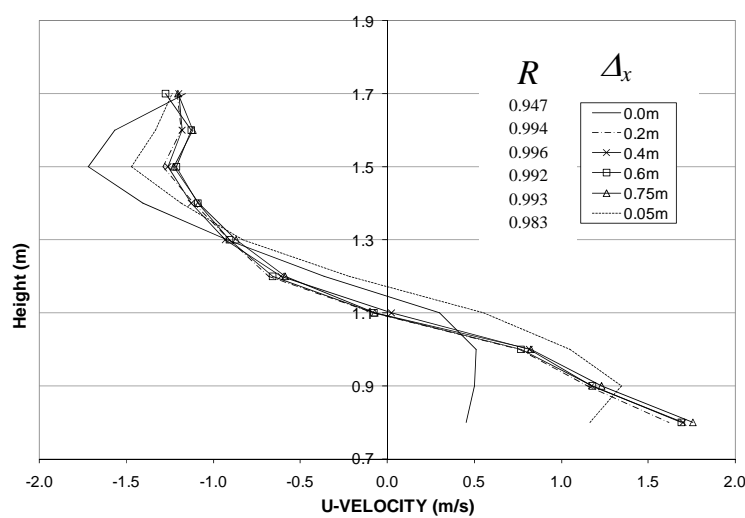

(c) Velocity profile at the window, $Q=500 \mathrm{~kW}$.

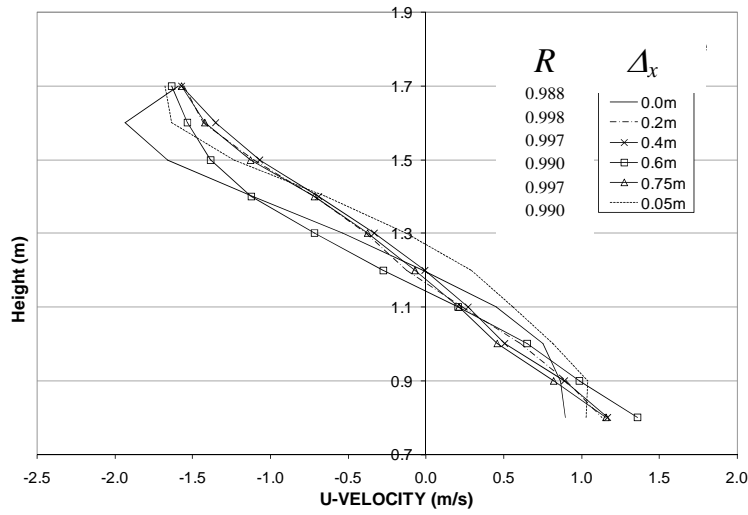

(e) Velocity profile at the window, $Q=1000 \mathrm{~kW}$.

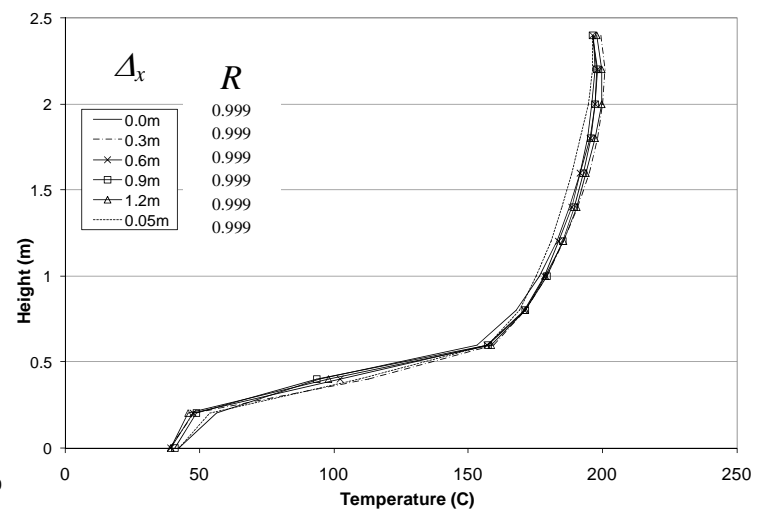

(b) Temperature profile in the corner, $Q=250 \mathrm{~kW}$.

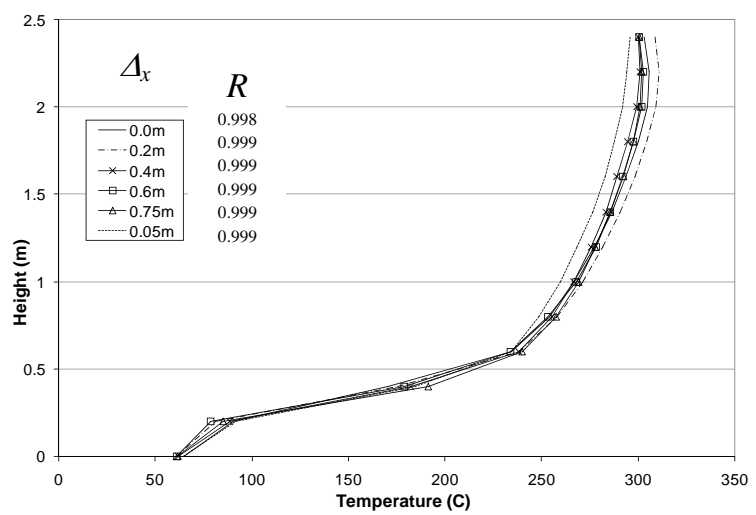

(d) Temperature profile in the corner, $Q=500 \mathrm{~kW}$.

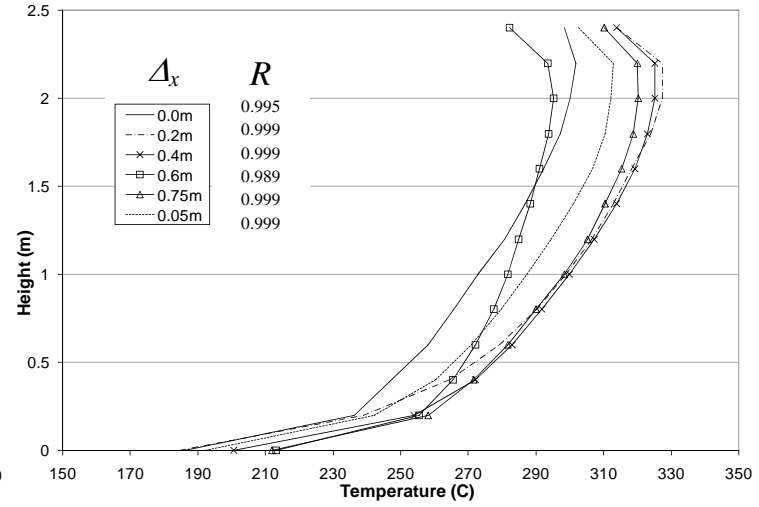

(f) Temperature profile in the corner, $Q=1000 \mathrm{~kW}$.

Fig. 7. Comparison of predicted parameter profiles using various domain extensions (the window vent). 


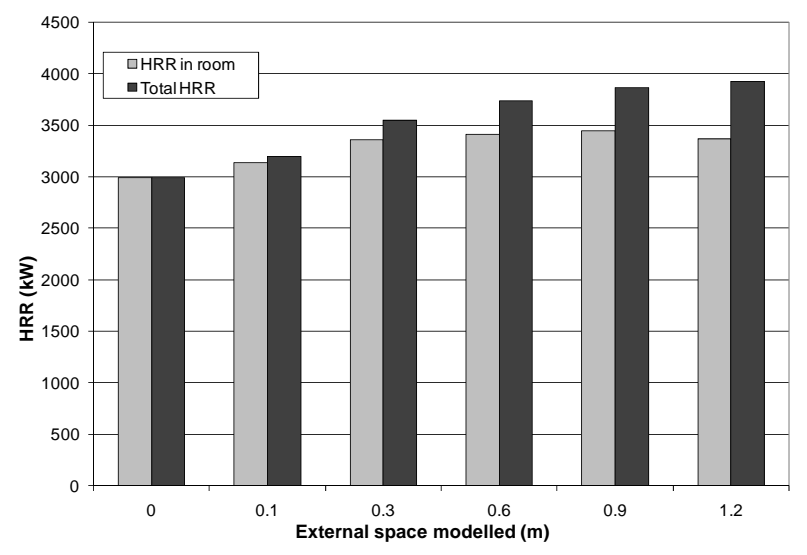

Fig. 8. Predicted total heat release rate and the heat release rate inside the room.

\section{CONCLUSION}

It has been demonstrated in the current study that the results of fluid dynamics computation are domain dependent as well as grid dependent. For compartment fire simulations, such dependence extends from fuel controlled fires to ventilation controlled fires.

Based on the results of this parametric study, it is recommended that the computational domain for a fuelcontrolled compartment fire simulation should be extended beyond vertical openings of the compartment by $1 / 2$ the hydraulic diameter of the largest opening in order to maintain the validity and minimize the inaccuracy of the simulation results. For ventilation-controlled fire simulations the recommended extension is one hydraulic diameter.

\section{FUTURE WORK}

The scope of the current study was limited to a relatively small compartment. It is recommended that the impact of domain extension on larger compartment fire simulations be investigated in the future. Future research should examine the impact of passive vents on cases where multiple openings and/or horizontal openings are present. The room geometry in the current study was limited to cases with infinitely thin and inert bounding walls and ceiling, and the effect of wall thickness and thermal properties of wall materials should also be explored. Comparisons with experimental results are required to confirm the validity and supremacy of domain extension.

\section{ACKNOWLEDGEMENT}

The authors would like to acknowledge the kind support of Mr Michael Lundqvist and DeFire Pty Ltd throughout this project.

\section{REFERENCES}

[1] Ewer, J.; Galea, E. R.; Patel, M. K.; Taylor, S.; Knight, B.; Petridis, M., (1999) SMARTFIRE: An Intelligent CFD Based Fire Model, Journal of Fire Protection Engineering, Vol. 10, No. 1, 13-27, doi:10.1177/104239159901000102

[2] Yau, R., Cheng, V., Lee, S., Luo, M. and Zhao, L., "Validation of CFD Models for Room Fires and Tunnel Fires”, Interflam 2001, International Interflam Conference, 9th Proceedings, Volume 1, September 17-19, 2001, Edinburgh, Scotland, Interscience Communications Ltd., London, England, 807-810 pp.

[3] Bounagui, A., Benichou, N., McGartney, C. and Kashef, A., "Optimizing the Grid Size Used in CFD Simulations to Evaluate Fire Safety in Houses," Proceedings of $3^{\text {rd }}$ NRC Symposium on 
Computational Fluid Dynamics, High Performance Computing and Virtual Reality, Ottawa, Ontario, Canada, 2003, pp. 1-8.

[4] Wang, J., Wu, Z., Xiao, X. and He, Y., (2005) Mesh Independence in Numerical Simulation of Building Fires, Fire Safety Science and Technology (Chinese), 24(3): 274-278.

[5] Wang, J., Hua, J., Kumar, K. and Kumar, S., (2006) Evaluation of CFD Modeling Methods for Fire-induced Airflow in a Room, Journal of Fire Sciences, 24: 393 - 411, doi:10.1177/0734904106061772

[6] Wen, J.X., Kang, K., Donchev, T. and Karwatzki, J.M., (2007) Validation of FDS for the Prediction of Medium-Scale Pool Fires. Fire Safety Journal, Vol. 42, No. 2, 127-138, doi:10.1016/j.firesaf.2006.08.007

[7] Wu, Z., Yang, M., Wang, J., and He, Y., 2006, "Selection of Computational Domain in Numerical Simulation of Building Fires”, Fire Safety Science and Technology (Chinese), Vol. 25, No. 4, pp.232-240.

[8] Steckler, K.D., Quintiere, J.G. and Rinkinen, W.J., "Flow Induced by Fire in a Compartment”, $19^{\text {th }}$ Symposium (International) on Combustion, Haifa, Israel, 1982, the Combustion Institute, pp. 913920.

[9] McGrattan, K., Klein, B., Hostikka, S. \& Floyd, J., “Fire Dynamics Simulator (Version 5) User’s Guide”, National Institute of Standards and Technology, NIST Special Publication 1019-5, 2007.

[10] Karlsson, B. and Quintiere, J.G., Enclosure Fire Dynamics, CRC Press LLC, Florida, 2000.

[11] Steckler, K. D., H. R. Baum and J. G. Quintiere, "Fire Induced Flows through Room Openings Flow Coefficients," Twentieth Symposium (International) on Combustion, the Combustion Institute, 1984, pp.1591-1600.

[12] He, Y., (1999) Measurement of Doorway Flow Field in Multi-Enclosure Building Fires, International Journal of Heat and Mass Transfer, 42(17): 3253-3265, doi:10.1016/S0017$\underline{9310(98) 00385-8}$

[13] McGrattan, K., Hostikka, S., Floyd, J., Baum, H. \& Rehm, R., "Fire Dynamics Simulator (Version 5) Technical Reference Guide”, NIST Special Publication 1018-5, National Institute of Standards and Technology, May 30, 2007.

[14] McGrattan, K., Hamins, A., Hostikka, S., Floyd, J. \& Klein, B., "Fire Dynamics Simulator (Version 5) Verification \& Validation Guide, Volume 1: Verification”, NIST Special Publication, National Institute of Standards and Technology, May 30, 2007.

[15] Dreisbach, J. and Hill, K., "Verification \& Validation of Selected Fire Models for Nuclear Power Plant Applications - Volume 7: Fire Dynamics Simulator”, NUREG-1824; EPRI 1011999; Volume 3; Electric Power Research Institute, Palo Alto, CA, U.S.A., May, 2007. 